This item was submitted to Loughborough's Research Repository by the author.

Items in Figshare are protected by copyright, with all rights reserved, unless otherwise indicated.

\title{
Effect of Ethyl Ester L-Lysine Triisocyanate addition to produce reactive PLA/PCL bio-polyester blends for biomedical applications
}

PLEASE CITE THE PUBLISHED VERSION

http://dx.doi.org/10.1016/j.jmbbm.2017.02.018

PUBLISHER

(C) Elsevier

VERSION

AM (Accepted Manuscript)

\section{PUBLISHER STATEMENT}

This work is made available according to the conditions of the Creative Commons Attribution-NonCommercialNoDerivatives 4.0 International (CC BY-NC-ND 4.0) licence. Full details of this licence are available at: https://creativecommons.org/licenses/by-nc-nd/4.0/

\section{LICENCE}

CC BY-NC-ND 4.0

\section{REPOSITORY RECORD}

Visco, Annamaria, Davide Nocita, Alberto Giamporcaro, Sara Ronca, Giuseppe Forte, Alessandro Pistone, and Claudia Espro. 2017. "Effect of Ethyl Ester L-lysine Triisocyanate Addition to Produce Reactive PLA/PCL Bio-polyester Blends for Biomedical Applications". figshare. https://hdl.handle.net/2134/24340. 


\title{
Effect of Ethyl Ester L-Lysine Triisocyanate addition to produce reactive PLA/PCL bio-polyester blends for biomedical applications
}

\author{
Annamaria Visco ${ }^{(1, *)}$, Davide Nocita ${ }^{(1)}$, Alberto Giamporcaro ${ }^{(1)}$, Sara Ronca ${ }^{(2)}$, Giuseppe Forte ${ }^{(2)}$, \\ Alessandro Pistone ${ }^{(1)}$, Claudia Espro ${ }^{(1)}$
}

(1) Department of Engineering, University of Messina,C.da Di Dio, 98166 Messina, Italy

(2) Department of Materials, Loughborough University, Loughborough, Leicestershire, UK, LE11 3TU

\begin{abstract}
We report in this paper the effects of Ethyl Ester L-Lysine Triisocyanate (LTI) on the physicalmechanical properties of Poly(lactide)/Poly(E-caprolactone) (PLA/PCL) polyesters blends. The PLA/PCL ratios considered were 20/80, 50/50 and 80/20 (wt/wt \%) and LTI was added in amounts of 0.0-0.5-1.0 phr. PLA and PCL reacted with LTI during processing in a Brabender twin screw internal mixer to produce block copolymers in-situ. The resulting blends have been characterized by torque measurements, uniaxial tensile tests, Differential Scanning Calorimeter, contact angle measurements with a Phosphate Buffered Saline (PBS) solution, ATR analysis and morphological SEM observations. Experimental results highlighted how LTI enhanced interaction and dispersion of the two components, resulting into a synergic effect in mechanical properties. Mechanical and physical properties can be tailored by changing the blend composition. The most noticeable trend was an increase in ductility of the mixed polymers. Besides, LTI decreased blend's wet ability in PBS and lowered the starting of crystalline phase formation for both polymers, confirming an interaction among them. These reactive blends could find use as biomedical materials, e.g. absorbable suture threads or scaffolds for cellular growth.
\end{abstract}

Keywords: bio-polyester; Poly(lactide); Poly ( $\varepsilon$ - caprolactone ); Reactive mixing; mechanical tensile test; wet ability.

(*) Corresponding author:

AnnamariaVisco - Associate professor of polymeric materials science

Department of Engineering,University of Messina- Contrada di Dio, Vill. S.Agata, I-98166 Messina, Italy.

Tel.: ++39 090 3977249; Fax: ++39 090 3977464; e-mail: avisco@unime.it 


\section{INTRODUCTION:}

Many types of bio-polyesters have been widely used in the last years, for the growing quest of sustainable materials and for various biological applications, in which they demonstrate to be very useful. One example is their use as absorbable sutures threads or scaffolds for cellular growth of various geometries [1-3].

Among this class of thermoplastic polymers, Poly (lactide) (PLA) and Poly ( $\varepsilon$ - caprolactone ) (PCL) are two of the most used polymers, well known for their bio-compatibility, biodegradability, and environmental sustainability (especially for PLA which can be obtained from renewable resources).

PLA, when not quenched, is a brittle polymer at room temperature, due to its glass transition being about $60^{\circ} \mathrm{C}$, and the situation worsen with time due to physical aging, but it shows high tensile strength if compared to other similar polyesters [4].

PCL, instead, has longer portions of $\mathrm{CH}_{2}$ units between the ester linkages, resulting in a more flexible structure and a lower glass transition temperature (about $-60^{\circ} \mathrm{C}$ ). This results in a rubberlike thermoplastic material with one of the highest ductility of its class [3,4].

The complementary characteristics of the two polyesters have given rise to a plethora of studies to obtain blends of PLA and PCL that could take advantage of their best properties. For applications, it would be highly desirable to obtain high yield stress and maximum stress in tensile conditions, moderate Young's modulus and high ductility [5,6].

However, the main problem to overcome is the very poor miscibility of PLA and PCL in the molten state, due to the high interfacial energy between the two macromolecules, that results into a "coalescence effect” and a very low dispersed morphology [1,2].

It has been proved that the dispersion is also strictly related on the processing method, and some physical blends with good dispersion of the PCL phase in the PLA matrix were obtained by injection molding [7].

Another possible mean to achieve good blends is the use of compatibilizers, such as "triblock" or "diblock" copolymers of the two polyesters, but this may require rather costly synthesis to achieve the right balance of the blocks for a given blend. [1,8].

A further method with a lower overall cost and high effectiveness is the "reactive mixing”. It consists in adding specific chemical agents, which can generate new chemical species during the thermo-mechanical processing of the materials. The chemical agents added to the blends can 
react with both polymers, creating 'in-situ' block copolymers that can act as phasecompatibilizer, sensibly lowering the interfacial energy between the two polymeric components and favoring their blending [3].

Other authors had already employed essential amino-acids derivates such as Ethyl Ester LLysine Triisocyanate (LTI) as reactive agents, to bring compatibilization between the two aliphatic polyesters. All of these studies demonstrate how, even at low amounts of LTI, the toughness of the blends, can be sensibly increased [4,9-10]. They have used different LTI amounts, generally 0,15-0,3-0,5 phr, but also higher amounts, such as $1 \mathrm{phr}$, and $2 \mathrm{phr}$, which, to our knowledge, is the maximum amount of this reactive agent used till now. The aim of their studies was the toughening of PLA and the improvement of both impact and bending strength, for generic applications.

The biocompatibility of lactide-caprolactone structures obtained by reaction with LTI has been confirmed by other studies on the characterization and synthesis of co-polyester-urethane networks for medical purpose and application [11-13]. In order to have an optimal performance of these materials, it's very important that also their degradation products are nontoxic and biocompatible. Robson et al. [14] have observed that the ultimate degradation products of bioabsorbable PLA-urethane based composites ( such as L-lysine and lactic acid) are nontoxic. Schreader at al. [15] highlighted the wide range of in-vivo applications of polyurethane based polymers (for scaffolds, hard tissue replacement, and biocompatible bone adhesive); both the invitro and in-vivo tests gave good results in terms of normal cells growth and immunological response. Zhang et al. [16] have suggested as well that a lysine diisocyanate based polymer is biodegradable and biocompatible, so that it can have biomedical applications.

Lactide-caprolactone structures could be employed in orthopedics field. One of the most common and most relevant problem in orthopedics is represented by infections, and consequent bio-film formation on the part, which can contribute to severe septic phenomena. A material showing proper mechanical characteristics, but able to biodegrade, could then be used as boneimplant and drug-delivery system (for instance an appropriate antibiotic delivery) without these issues.

Furthermore, to have an appropriate alternative to metals that is able to biodegrade, could avoid further surgeries targeted to remove the implant, which in some cases can be a source of concern for the patient. For those reasons a blend of bio-polyesters with proper mechanical 
characteristics and long term dissolving feature, could prove very useful for this application. Improved mechanical properties in terms of strength and of stiffness, can be obtained by crosslinking with a polyfunctional compatibilizing agent, such as the LTI, and/or with a filler composed by nanoparticles like hydroxyapatite. A grade of entirely laevogyrate Poly(lactide) (PLLA) could also be used since its elastic modulus value is in the range of 4GPa [17].

The change in mechanical properties of polymer blends and polymer composites is commonly analyzed by bulk analyses, such as static tensile mechanical tests. However, it can be also detected by local surface measurements techniques, such as the nanoindentation one [18]. For example Pillin at al. [19] highlighted that nanoindentation can be more accurate to detect changes in mechanical properties than macroscopical tests because during the degradation of PLA, low molecular weight chains diffuse toward interfaces and are preferentially located at the surfaces probed by this technique.

In the literature however, at present there is a lack of a deep physical and mechanical characterization of these reactive blends as a function of their composition. Generally, mechanical investigation on bio-polymers, pure or in blend, is very important in order to know key mechanical characteristics such as yield strength, modulus, toughness, and fracture properties [9, 20-21]. For these reason, we undertook a systematic study of the PLA/PCL blends, pure and with different amounts of LTI added, in various compositions. We have studied torque values on the mixer screws during mixing, mechanical tensile properties, thermal behavior, and wet ability in a fluid simulating the animal tissues conditions (Phosphate Buffered Saline Solution or PBS). The change in chemical structure has been followed by FT-IR and the dispersion of the two polymeric phases has been observed by SEM microscopy. Our aim was to control the microstructure of these reactive blends, and hence the macroscopic features of these materials, by setting and tailoring their composition. The results obtained can give a better understanding of the physic-mechanical properties of these blends and help for their correct application in the biomedical field. 


\section{2 - MATERIALS AND METHODS}

\subsection{Materials}

PLA/PCL, i.e. blends and PLA/PCL/LTI reactive blends (obtained by adding the reactive compatibilizing agent in various amounts), were produced from:

-Poly(lactide) - code: PLA (solid pellets, BioFlex- 6510 supplied by FKUR( $\left.\overline{\mathrm{M}}_{\mathrm{n}}=197000 \mathrm{Da}\right)$; -Poly (ع-caprolactone)-PCL (solid pellets, purchased from Sigma-Aldrich (IT) $\overline{\mathrm{M}}_{n}=80000 \mathrm{Da}$ ); -Ethyl Ester L-Lysine Triisocyanate- LTI (Liquid, optical purity 80, purchased from Infine Chemicals ltd).

The polyesters were dried at $50^{\circ} \mathrm{C}$ overnight before processing; LTI was used as received. The Phosphate Buffered Saline solution (PBS, purchased from Sigma-Aldrich) was obtained by dissolving a tablet composed by phosphate salts in $200 \mathrm{~mL}$ of distilled water.

\subsection{Blends and sample preparation}

Materials were first mixed in an internal mixer, the Brabender Plasticorder PL200 at $180{ }^{\circ} \mathrm{C}, 25$ rpm for 15 minutes; the reactive blends were obtained by adding LTI 5 minutes after the mixing started in the Brabender, following the conditions described by Tuba et al. [9]. Those processing parameters represent the less demanding but still effective conditions described in the literature to obtain PLA-based reactive blends, since its well-known sensitivity to thermo-mechanical degradation.

All solid blends were compression molded at $180^{\circ} \mathrm{C}$ and 100 bars for 10 minutes by a hot press inside a stainless steel mold of $12 \mathrm{cmx} 12 \mathrm{~cm}$ dimensions, $1 \mathrm{~mm}$ thickness (Campana s.r.l.), with teflon releasing films (126 microns thickness) supplied by P.A.T.I. srl, and then cooled by a water cooling system. The tensile test samples were obtained by a Ray-Ran cutter in conformity with ASTM D-638 standard for sample shapes.

Blends of various composition of polyesters (wt. \%) and various amounts of LTI in phr (per hundred resin, $0.0 \mathrm{phr}$ or un-compatibilized, $0.5 \mathrm{phr}$ and $1.0 \mathrm{phr}$ ) were produced and the components identified by a code containing “A” for PLA , “C” for PCL , and "T" for LTI . Each letter is followed by a number, which indicates the percentage of the polymer and the LTI phr amount. A100 and C100 samples are pure PLA and pure PCL; they have been processed in the 
Brabender mixer in the same conditions of the blends. All the blends produced and studied are listed and codified in Table 1.

Table I - Blends code

\begin{tabular}{c|cccc}
\hline Code & $\begin{array}{c}\text { PLA } \\
\text { (wt. \%) }\end{array}$ & $\begin{array}{c}\text { PCL } \\
\text { (wt. } \%)\end{array}$ & $\begin{array}{c}\text { LTI } \\
\text { (phr) }\end{array}$ & $\begin{array}{c}\text { Torque } \\
\text { at 15 minutes } \\
\text { (N*m) }\end{array}$ \\
\hline A100 & 100 (pure) & 0 & - & 9.02 \\
C100 & 0 & 100 (pure) & - & 6.54 \\
\hline A80C20 & 80 & 20 & 0 & 7.56 \\
A80C20T05 & 80 & 20 & 0,5 & 12.79 \\
A80C20T1 & 80 & 20 & 1 & 20.94 \\
\hline A50C50 & 50 & 50 & 0 & 7.44 \\
A50C50T05 & 50 & 50 & 0,5 & 10.44 \\
A50C50T1 & 50 & 50 & 1 & 14.18 \\
\hline A20C80 & 20 & 80 & 0 & 6.74 \\
A20C80T05 & 20 & 80 & 0,5 & 8.94 \\
A20C80T1 & 20 & 80 & 1 & 10.26 \\
\hline
\end{tabular}

\subsection{Characterization and testing}

Torque measurement during mixing is an index of the changing viscosity of the blends in the molten state; it was read and recorded by the Torque transducer of the Brabender Plasticorder PL2000, interfaced with the PC Brabender software. It provided torque values expressed in $\mathrm{N}^{*} \mathrm{~m}$ every $30 \mathrm{~s}$, for all the 15 min duration of the mixing process.

Uniaxial tensile tests were conducted by Lloyd LR10K universal testing machine, following the standard ASTM D638-10 with type V specimens and crosshead speed of testing of $10 \mathrm{~mm} / \mathrm{min}$. This was found to be the ideal speed of testing for all the blends made, considering the great difference in ductility between the two pure polyesters. The mechanical parameters investigated were: Young modulus (E, MPa), stress at yielding $\left(\sigma_{\mathrm{y}}, \mathrm{MPa}\right)$ stress at break $\left(\sigma_{\mathrm{b}}, \mathrm{MPa}\right)$ and maximum stress ( $\left.\sigma_{\max }, \mathrm{MPa}\right)$, elongation at yielding $\left(\varepsilon_{\mathrm{y}}, \%\right)$ and at break $\left(\varepsilon_{\mathrm{b}}, \%\right)$, and the work at break $\left(\mathrm{W}_{\mathrm{b}}, \mathrm{J}\right)$. 
Wet ability measurements were obtained using the "Sessile drop method" using a prototype of the "Polymer laboratory" at University of Messina. Drops of $5 \mu$ Lof the Phosphate buffered saline (PBS) solution prepared in advance of the testing were deposited on the sample surface. Each drop image was measured by means of the software Image J [22].

FT-IR and ATR spectroscopic analyses were conducted using a Shimadzu FT-IR, on films of about 50 microns in thickness. 64 scans from 600 to $4000 \mathrm{~cm}^{-1}$ were acquired with a resolution of $4 \mathrm{~cm}^{-1}$.

Thermal analyses were conducted by means of Differential Scanning Calorimetry using a TA Instruments DSC Q100, from room temperature to $200^{\circ} \mathrm{C}$, with a heating rate of $10{ }^{\circ} \mathrm{C} / \mathrm{min}$ and water cooling. The crystalline degree of PCL, $\chi$, was calculated using the following equation:

$$
\chi=\frac{\Delta H_{m}}{\varphi \cdot \Delta H_{0}}
$$

where $\Delta \mathrm{H}_{\mathrm{m}}[\mathrm{J} / \mathrm{g}]$ is melting enthalpy, $\varphi$ is the weight fraction of the studied material and $\Delta \mathrm{H}_{\mathrm{o}}$ $[\mathrm{J} / \mathrm{g}]$ is the theoretical enthalpy of fusion of a polymer crystal of infinite extension [9].

Initial crystalline fraction of PLA, $\chi_{\mathrm{i}}$, was calculated using the following equation:

$$
\chi_{i}=\frac{\Delta H_{m}-\Delta H_{c c}}{\varphi \cdot \Delta H_{0}}
$$

where $\Delta \mathrm{H}_{\mathrm{cc}}[\mathrm{J} / \mathrm{g}]$ is the "cold-crystallization” enthalpy of PLA,. Cold crystallization is due to the well-known phenomenon of PLA re-organization in more ordered regions induced by the thermal heating of DSC test [9]. For this reason equation 3 has been used to calculate the crystalline degree of the cold crystallized PLA $\left(\chi_{\mathrm{cc}}\right)$ :

$$
\chi_{c c}=\frac{\Delta H_{c c}}{\varphi \cdot \Delta H_{0}}
$$

Finally, Scanning Electron Microscopy (SEM) images were obtained using a FEI Quanta FEG 450 microscope operating with an accelerating voltage of $5 \mathrm{kV}$ in low vacuum mode and placing the samples on aluminum holders by means of a graphitic adhesive. 


\section{3 - RESULTS AND DISCUSSION}

\section{1- Torque measurements during the blend mixing}

Torque values during mixing are strictly related to the melt viscosity of thermoplastic materials; a change in these values during time suggests modifications in the structure of the polymers, for instance in the molecular weight or, generally, in the macromolecular structure.

In figure 1,a torque value vs mixing time of all the un-compatibilized blends is shown. Torque values are low and constant for "rich in PCL" blends (C100, A20C80 and A50C50), around 6-7 $\mathrm{N} \cdot \mathrm{m})$; in pure PLA sample(A100) it became the highest one $(9.02 \mathrm{~N} \cdot \mathrm{m})$ with a rapid decrease during time. A similar but less rapid behavior is shown in the "rich in PLA" blend (A80C20). So, two different trends are evident, due to the higher thermo-mechanical degradation resistance of PCL with respect to PLA. Thus PLA confirmed to be susceptible to thermo-mechanical degradation, most likely due to degradation in its molecular weight with time. In figure 1,b torque values of the A50C50 blend before and after the addition of different amount of compatibilizer (LTI) are plotted. In this case, the presence of compatibilizer induces a great increment of all torque values (as indicated by the arrow in the graph) that increases with the addition of higher amounts of LTI, suggesting the formation of high molecular weight compounds in the blend. In table I are listed the torque values after 15 minutes of processing for all the investigated blends. Experimental data indicate that the changes are proportional to the LTI amount. Similarly, the other blends (A20C80 and A80C20) show a progressive increase in torque values with increasing the LTI amount (see table I). The graphs, not shown for brevity, confirms again the formation of a higher-molecular weight component in all the blends.

\section{2- Mechanical features of the blends}

Table II lists the mechanical parameter values of pure materials. Pure PCL (C100) has a great ductility, with elongation at break values ( $\varepsilon_{\mathrm{b}}$ ) of about $1400 \%$. Instead $\varepsilon_{\mathrm{b}}$ decreased of $\sim 15 \%$ in pure PLA (A100), which has higher stiffness than PCL ( $8156 \mathrm{MPa}$ and $150 \mathrm{MPa}$, respectively). 
Table II- Mechanical parameters of pure materials

\begin{tabular}{c|ccccccc}
\cline { 2 - 7 } Code & $\begin{array}{c}\mathbf{E} \\
{[\mathbf{M P a}]}\end{array}$ & $\begin{array}{c}\boldsymbol{\varepsilon}_{\mathbf{y}} \\
{[\mathbf{\%}]}\end{array}$ & $\begin{array}{c}\boldsymbol{\sigma}_{\mathbf{y}} \\
{[\mathbf{M P a}]}\end{array}$ & $\begin{array}{c}\boldsymbol{\sigma}_{\mathbf{m a x}} \\
{[\mathbf{M P a}]}\end{array}$ & $\begin{array}{c}\boldsymbol{\varepsilon}_{\mathbf{b}} \\
{[\mathbf{\%}]}\end{array}$ & $\begin{array}{c}\boldsymbol{\sigma}_{\mathbf{b}} \\
{[\mathbf{M P a}]}\end{array}$ & $\begin{array}{c}\mathbf{W}_{\mathbf{b}} \\
{[\mathbf{J}]}\end{array}$ \\
\hline PLA & 640 & 9,05 & 28,09 & 28,09 & 35,42 & 20,62 & 0,30 \\
Stand. dev. & \pm 63 & $\pm 0,9$ & $\pm 2,13$ & $\pm 2,13$ & $\pm 3,1$ & $\pm 1,83$ & $\pm 0,03$ \\
A100 & 816 & 6,07 & 22,36 & 22,36 & 14,89 & 15,23 & 0,08 \\
Stand. dev. & \pm 76 & $\pm 0,5$ & $\pm 1,74$ & $\pm 1,74$ & $\pm 1,2$ & $\pm 0,89$ & $\pm 0,008$ \\
\hline PCL & 155 & 19,5 & 10,94 & 42,36 & 1518 & - & - \\
Stand. dev. & \pm 12 & $\pm 1,9$ & $\pm 0,9$ & $\pm 2,76$ & \pm 155 & - & - \\
C100 & 154 & 19,46 & 14,00 & 43,00 & 1405 & 39,82 & 10,81 \\
Stand. dev. & \pm 14 & $\pm 1,4$ & $\pm 0,59$ & $\pm 1,04$ & $\pm 46,37$ & $\pm 1,19$ & $\pm 1,03$ \\
\hline
\end{tabular}

Table II lists the mechanical tensile parameters of PLA and PCL (not processed) and processed in the Brabender Plasticorder (A100 and C100).PLA is susceptible to thermo-mechanical degradation, since it becomes even more brittle after processing. This is suggested by the increase in stiffness ( from $\sim 640 \mathrm{MPa}$ to $\sim 816 \mathrm{MPa}$ ), the decrease in deformability ( from $~ 35 \%$ to $\sim 15 \%$ ), in strength ( from $20 \mathrm{MPa}$ to $15 \mathrm{MPa}$ ) and in yielding ( from $28 \mathrm{MPa}$ to $22 \mathrm{MPa}$ ). Instead PCL retained its features after its processing confirming its high thermo-mechanical degradation resistance.

In figure 2 the stress/strain curves of pure materials and of un-compatibilized blends are plotted in order to observe their difference in tensile behavior. In particular blends rich in PCL (as the A20C80 blend), exhibit a great ductility, with elongation at break values of $\sim 850 \%$. Instead elongation at break decreases up to values of $~ 12 \%$ in PLA rich blend (as the A80C20 blend). Young modulus is much higher in PLA-rich blend than in PCL one ( 380 MPa and 150 MPa, respectively),as expected. The A50C50 blend has got intermediate properties.

In table III, the mechanical parameters of each blend before and after the addition of 0.5 and 1.0 phr of LTI are reported. The presence of 1 phr of LTI greatly improves all the properties of the three polyester blends, as suggested by the percentage variation of mechanical parameters (indicated in the table by the symbol: $\delta_{\text {Pure-T1}}$ ), calculated as difference between each parameter value of pure samples subtracted to the same parameter value of $\mathrm{T} 1$ blends. 
These changes occur in all the blends but are particularly evident in the blend A50C50, where the mechanical features of the un-compatibilized blend where, as expected, the worse in the series due to the immiscibility of the PCL and PLA (see data in table III).

In particular, the A50C50T1 blend exhibits significant enhancements in yield stress (of $145 \%$ ), deformation at yield (of 438\%), elongation at break (of 6254\%), and work of fracture (of $28500 \%)$.

It should be also considered that, as LTI can react randomly with both PCL and PLA, the probability to form a block copolymer having at least one PCL and one PLA (the best to actually act as a compatibilizer) is higher in the A50C50 blend, compared to the blends with higher content of PCL or PLA.

The observed improvements are due to the enhanced dispersion of one polymeric phase in the other one. This is well visible in figure 3 where SEM micrographs of A50C50 without and with LTI compatibilizer are shown. Figure 3a shows big particles, circular in shape and about 12 microns wide; suggesting a polymeric phase separated from the other one due to the poor miscibility.

Table III - Mechanical properties of the blends

\begin{tabular}{c|ccccccc}
\hline \multicolumn{1}{c}{ Code } & $\begin{array}{c}\mathbf{E} \\
{[\mathbf{M P a}]}\end{array}$ & $\begin{array}{c}\boldsymbol{\varepsilon}_{\mathbf{y}} \\
{[\%]}\end{array}$ & $\begin{array}{c}\boldsymbol{\sigma}_{\mathbf{y}} \\
{[\mathbf{M P a}]}\end{array}$ & $\begin{array}{c}\boldsymbol{\sigma}_{\text {max }} \\
{[\mathbf{M P a}]}\end{array}$ & $\begin{array}{c}\boldsymbol{\varepsilon}_{\mathbf{b}} \\
{[\mathbf{\%}]}\end{array}$ & $\begin{array}{c}\boldsymbol{\sigma}_{\mathbf{b}} \\
{[\mathbf{M P a}]}\end{array}$ & $\begin{array}{c}\mathbf{W}_{\mathbf{b}} \\
{[\mathbf{J}]}\end{array}$ \\
\hline $\begin{array}{c}\text { A80C20 } \\
\text { A80C20T05 }\end{array}$ & $386 \pm 48$ & $5,0 \pm 0,9$ & $12,7 \pm 1,1$ & $18,07 \pm 0,7$ & $13 \pm 0,9$ & $16,9 \pm 1,2$ & $0,05 \pm 0,01$ \\
A80C20T1 & $506 \pm 39$ & $8,6 \pm 0,7$ & $25,2 \pm 0,7$ & $34,07 \pm 1,2$ & $360 \pm 22$ & $33,9 \pm 1,2$ & $3,33 \pm 0,2$ \\
\hline $\boldsymbol{\delta}_{\text {Pure-T1 }[\%]}$ & $\mathbf{3 1}$ & $\mathbf{7 2}$ & $\mathbf{9 8}$ & $\mathbf{8 8}$ & $\mathbf{2 7 2 9}$ & $\mathbf{1 0 0}$ & $\mathbf{6 5 6 0}$ \\
\hline A50C50 & $334 \pm 36$ & $3,9 \pm 0,7$ & $7,2 \pm 0,6$ & $10 \pm 0,9$ & $10 \pm 2,0$ & $9,6 \pm 0,6$ & $0,02 \pm 0,01$ \\
A50C50T05 & $264 \pm 47$ & $27,1 \pm 8,15$ & $13,2 \pm 1,1$ & $21,8 \pm 2,8$ & $446 \pm 81$ & $21,6 \pm 2,8$ & $3,05 \pm 0,9$ \\
A50C50T1 & $370 \pm 51$ & $21,1 \pm 5,57$ & $17,6 \pm 1,2$ & $39,02 \pm 2,1$ & $646 \pm 39$ & $38,8 \pm 2,1$ & $5,72 \pm 0,4$ \\
\hline $\boldsymbol{\delta}$ Pure-T1 [\%] & $\mathbf{1 1}$ & $\mathbf{4 3 9}$ & $\mathbf{1 4 5}$ & $\mathbf{2 9 0}$ & $\mathbf{6 2 5 5}$ & $\mathbf{3 0 6}$ & $\mathbf{2 8 5 0 0}$ \\
\hline A20C80 & $159 \pm 23$ & $20,4 \pm 4,92$ & $11,4 \pm 0,6$ & $21,76 \pm 1,0$ & $851 \pm 46$ & $21,35 \pm 1,2$ & $4,98 \pm 0,4$ \\
A20C80T05 & $179 \pm 41$ & $20,4 \pm 2,65$ & $12,7 \pm 0,7$ & $35,88 \pm 3,5$ & $1052 \pm 94$ & $35,53 \pm 3,5$ & $9,12 \pm 1,5$ \\
A20C80T1 & $211 \pm 56$ & $16,7 \pm 1,97$ & $16,4 \pm 0,4$ & $51,97 \pm 2,0$ & $1090 \pm 47$ & $51,75 \pm 2,1$ & $10,01 \pm 0,9$ \\
\hline $\boldsymbol{\delta}_{\text {Pure-T1 [\%] }}$ & $\mathbf{3 3}$ & $\mathbf{- 1 8}$ & $\mathbf{4 3}$ & $\mathbf{1 3 9}$ & $\mathbf{2 8}$ & $\mathbf{1 4 2}$ & $\mathbf{1 0 1}$ \\
\hline
\end{tabular}


The presence of $0.5 \mathrm{phr}$ (figure 3b) and $1.0 \mathrm{phr}$ (figure 3c) of LTI progressively reduces the particles dimension that become of $\sim 3 \mu \mathrm{m}$ and $1 \mu \mathrm{m}$, respectively. The high dispersion is well visible in figure $3 \mathbf{c}$ that appears quite homogeneous; this time is also visible a stress preferential direction imposed by the spinning force generated inside the mixing chamber.

This stress preferential direction is not visible in the first micrograph (figure 3a) and just outlined in the intermediate picture (figure $\mathbf{3 b}$ ). It is interesting to note that this stress is completely lost after the molding step for the un-compatibilized blend, while it is retained in the presence of LTI.

The blend rich in PCL (A20C80) improves in strength after addition of 1.0 phr of LTI: the $\sigma_{\max }$ value grows of $\sim 139 \%$ and $\sigma_{b}$ value grows of $\sim 142 \%$. Then, the blend rich in PLA (A80C20) improves in ductility after $1.0 \mathrm{phr}$ of LTI addition: the $\sigma_{\mathrm{y}}$ value grows of $\sim 98 \%, \varepsilon_{\mathrm{b}}$ grows of $\sim 2730 \%$ and $\mathrm{W}_{\mathrm{b}}$ of $\sim 6500 \%$.

This suggest that the main improvement brought by the presence of LTI in the blends, is mostly on ductility, for those blends that were originally brittle, and in mechanical strength for those blends which were originally ductile but weaker. The synergic effect observed between the very different properties of PLA and PCL confirms that a good dispersion and compatibility are reached.

The stress strain curves, reported in Fig. 4, show the considerable improvements in ductility of the three blends after the addition of 1 phr of reactive agent, as indicated by the arrows.

The un-compatibilized blends are represented by a continuous line while the 1 phr compatibilized ones are represented by a dashed line of the same color. The formation of the copolyester-urethanes acts as compatibilizer and emulsifying agent, lowering the interfacial tension between the two polyesters (PCL and PLA).

In figure 5 the photographs of the dog-bone samples before and after a tensile test, are reported. In particular we can notice the difference in color of the PCL sample (C100) that's whiter than the PLA one (A100). The A50C50 blends became progressively darker (brown color) with increasing amount of LTI. The picture of the same samples before the tensile test highlights the considerable elongation at break of the PCL sample (C100) and the improved ductility of the A50C50 blend compatibilized with 1.0 phr of LTI, according to the results shown in the graph of figure 4 . 
In this research, the selected grades of investigated poly(lactide) and the poly(caprolactone) are chosen to have moderate stiffness, more suitable for suture applications. It is known that the remodeling process during wound healing at the suture sites is helped by a moderate strain field on the part [13]. For this reason, a PLLA grade with an Elastic Modulus in the order of GPa could be too rigid for sutures applications [17].

The graphs shown in Figure 6 compare some of the properties of un-compatibilized and compatibilized blends, as a function of the PCL content. The values change with the composition of the blends. The reactive mixing that occurs after LTI adding, progressively improves all the mechanical properties such as the work at fracture (fig.6a), maximum stress (fig.6b), stress at yielding (fig.6c) and Young modulus (fig.6d), as indicated by the arrows in each graph.

The results shown suggest that this method can be used not just for improving PLA ductility or PCL strength, but mostly widely to obtain materials within a large range of properties deriving from both the polyesters, simply by changing the blend composition.

For example, if we consider applications in the biomedical field, for soft tissues, we would require materials which show low stiffness, and high ductility. For this purpose, the formulation could be composed by higher PCL content and lower LTI amount. This formulation can grant a moderate stress field on the tissue, maintaining an appreciable tensile strength, so that these materials could be successfully employed as internal surgery sutures $[\mathbf{1 3}, 23]$.

If instead higher stiffness and yield strength materials are needed, for instance in orthopedic applications like bone implants in forms of scaffolds for cellular growth, blends with high PLA and LTI content would be the most suitable materials [24].

\subsection{Thermal properties}

Thermal analysis results are shown in figure 7a,b and given in details in tables IV and V.

Table IV indicates melting temperature $\left(\mathrm{T}_{\mathrm{m}}\right)$ and enthalpy $\left(\Delta \mathrm{H}_{\mathrm{m}}\right)$ of PCL, cold crystallization temperature $\left(\mathrm{T}_{\mathrm{cc}}\right)$ and enthalpy $\left(\Delta \mathrm{H}_{\mathrm{cc}}\right)$ of PLA, in all the studied blends. The PLA fraction shows two phase transitions which are associated to cold crystallization (at about $104-113^{\circ} \mathrm{C}$ ) and melting. The latter is composed by two components: one due to the initial crystalline order of PLA (at $\sim 153^{\circ} \mathrm{C}-157^{\circ} \mathrm{C}$ ) and the second due to cold crystallized component induced during 
calorimetric test heating (at about $145^{\circ} \mathrm{C}-149^{\circ} \mathrm{C}$ ). The correspondent peaks are indicated in the graphs reported in figure 7 a.

Table IV-Calorimetric DSC parameters of all the studied blends

\begin{tabular}{|c|c|c|c|c|c|c|c|}
\hline \multirow[b]{2}{*}{ CODE } & PCL & \multicolumn{6}{|c|}{ PLA } \\
\hline & $\begin{array}{l}\mathrm{Tm} \\
{ }^{\circ} \mathrm{C} \\
\end{array}$ & $\begin{array}{c}\Delta \mathrm{Hm} \\
\mathrm{J} / \mathrm{g}\end{array}$ & $\begin{array}{c}\text { Tcc } \\
{ }^{\circ} \mathrm{C} \\
\end{array}$ & $\begin{array}{c}\Delta \mathrm{Hec} \\
\mathrm{J} / \mathrm{g}\end{array}$ & & & $\begin{array}{l}\Delta \mathrm{Hm} \\
\mathrm{J} / \mathrm{g}\end{array}$ \\
\hline A80C20 & 62,25 & 15,51 & 104,16 & 12,32 & 147,73 & 155,94 & 13,41 \\
\hline A80C20T05 & 62,39 & 17,27 & 107,72 & 12,17 & 148,38 & 156,28 & 13,78 \\
\hline A80C20T1 & 59,45 & 11,31 & 113,73 & 12,92 & 149,75 & 153,51 & 13,65 \\
\hline A50C50 & 64,02 & 39,68 & 103,61 & 7,24 & 146,65 & 155,74 & 9,45 \\
\hline А50С50T05 & 62,83 & 35,57 & 111,05 & 6,21 & 148,31 & 154,37 & 8,35 \\
\hline A50C50T1 & 62,08 & 32,43 & 113,05 & 7,11 & 148,88 & 157,14 & 8,33 \\
\hline A20C80 & 64,54 & 56,11 & 105,85 & 3,53 & 145,97 & 154,12 & 3,55 \\
\hline А20С80T05 & 63,63 & 54,19 & 107,44 & 0,89 & 147,01 & 153,99 & 3,37 \\
\hline A20C80T1 & 60,92 & 48,67 & 111,79 & 0,61 & 146,6 & 156,7 & 2,88 \\
\hline
\end{tabular}

Calorimetric data highlight as the LTI presence changes the melting temperatures of both PCL and PLA. In particular, $\mathrm{T}_{\mathrm{m}}$ value of PCL in all the blends decreases with increasing the LTI content (from about $62^{\circ} \mathrm{C}$ to $59^{\circ} \mathrm{C}$, from about $64^{\circ} \mathrm{C}$ to $62^{\circ} \mathrm{C}$ and from about $64^{\circ} \mathrm{C}$ to $60^{\circ} \mathrm{C}$ in the A80C20, A50C50 and A20C80 blend, respectively). Also the correspondent $\Delta \mathrm{H}_{\mathrm{m}}$ decreases from $\sim 15$ to $11.3 \mathrm{~J} / \mathrm{g}$, from $\sim 39$ to $\sim 32 \mathrm{~J} / \mathrm{g}$ and from $\sim 56$ to $\sim 48 \mathrm{~J} / \mathrm{g}$.

Table V-Crystalline degree of PLA and PCL in all the studied blends

\begin{tabular}{c|ccc}
$\begin{array}{c}\text { Blend } \\
\text { code }\end{array}$ & $\begin{array}{c}\chi_{\text {iPLA }} \\
(\%)\end{array}$ & $\begin{array}{c}\chi_{\mathbf{c c}_{\text {PLA }}} \\
(\%)\end{array}$ & $\begin{array}{c}\chi_{\text {PCL }} \\
(\%)\end{array}$ \\
\hline A80C20 & 1,01 & 11,41 & 54,42 \\
A80C20T05 & 1,49 & 11,27 & 60,6 \\
A80C20T1 & 0,68 & 11,96 & 39,68 \\
\hline A50C50 & 3,28 & 10,72 & 55,69 \\
A50C50T05 & 3,17 & 9,2 & 49,92 \\
A50C50T1 & 1,81 & 10,53 & 45,52 \\
\hline A20C80 & 0,08 & 13,08 & 49,22 \\
A20C80T05 & 9,2 & 3,29 & 47,54 \\
A20C80T1 & 8,4 & 2,26 & 42,69 \\
\hline
\end{tabular}


Similarly, the two melting peaks of PLA change in all the blends with increasing the LTI content. For example in the A80C20 blend, the melting peaks at $\sim 147^{\circ} \mathrm{C}$ and $\sim 156^{\circ} \mathrm{C}$, became $\sim 149^{\circ} \mathrm{C}$ and $\sim 153^{\circ} \mathrm{C}$ in the A80C20T1 blend. Or similarly, in the A20C80 blend, the peaks are initially at $\sim 145^{\circ} \mathrm{C}$ and $\sim 154^{\circ} \mathrm{C}$ and became $\sim 146^{\circ} \mathrm{C}$ and $\sim 157^{\circ} \mathrm{C}$ in the A20C80T1. Enthalpy values generally decreases (for example from 9.45 to $8.33 \mathrm{~J} / \mathrm{g}$, in the A50C50 blend, and from 3.55 to 2.88 in the A20C80 blend) while it's constant in the A80C20 blend, around $13 \mathrm{~J} / \mathrm{g}$. Due to the presence of two peaks for two different contributes, it's difficult to clearly interpret the peaks' trend of PLA melting. They also changes in shapes, as visible in the expansion of figure 7, suggesting a re-organization inside the material.

In the presence of LTI, the cold crystallized component for PLA decreases in enthalpy, while the melting peak increases in temperature. For example, $\Delta \mathrm{H}_{\mathrm{cc}}$ and $\mathrm{T}_{\mathrm{cc}}$ of $\mathrm{A} 20 \mathrm{C} 80$ blend are about $3,5 \mathrm{~J} / \mathrm{g}$, and $105^{\circ} \mathrm{C}$ respectively and about $0,6 \mathrm{~J} / \mathrm{g}$ and $111^{\circ} \mathrm{C}$ in the of A20C80T1 blend.

Calorimetric experimental data have confirmed that PCL has an higher crystalline order than PLA in all the studied blends, as shown in table V. In fact, the crystalline degree of PCL is generally within the range of $\sim 42 \%$ (min) - $60 \%$ (max) while the initial PLA crystalline degree is within the range of $\sim 0.08 \%$ ( $\min$ ) $-9.2 \%$ (max). PLA crystalline degree improved after its cold crystallization up to $\sim 2.26 \%$ ( $\min$ ) $-13.08 \%$ ( $\max$ ) .

These experimental results highlight an overall change in the polymeric blend structure induced by LTI presence, due to a macromolecular re-organization. This further confirm the idea that LTI creates grafted and/or cross linked structures which are reasonably more amorphous or disordered than the pure blends. In order to investigate and explain all effects induced by LTI on the crystallinity of both PLA and PCL, further investigations will be performed in blends with LTI content higher than 1 phr.

\subsection{Wet-ability}

Wet ability tests indicate the kind of interactions between a solid substrate and a liquid substance: the lower is the contact angle between the two, the more is their interaction. This lowers the interfacial tension and lets an absorption of liquid in the polymeric material.

For highly biodegradable materials, an higher interaction between fluid and material substrate suggests an higher degradation rate due to hydrolytic reactions, changing the material's physical 
properties. Generally, the contact angle values depend on various factors like the crystalline degree of the polymer substrate, the viscosity of the liquid, the surface features on the interface, and the ambient conditions for this kind of testing; their contribution can establish liquid diffusion inside the solid material, and so its degradation rate

The graph in Figure 8 shows how the increasing amount of PCL in the PLA/PCL blends brings an increase in contact angle regardless of the LTI amount. This is clearly related to the lower hydrophilic behavior of PCL (with respect to the PLA) due to its higher crystallinity, and to its lower amount of hydrophilic groups (the hydroxyl ones at the end of the chains and ester bonds in the macromolecules). Furthermore, in the same picture, it can be noticed how the compatibilized blends (T0.5 and T1), exhibit an increased contact angle compared to the corresponding un-compatibilized ones (T0). This can be related to the new co-polyester-urethane networks, which should have a more hydrophobic behavior due to a change in structural composition that lowers the interaction between the liquid and the substrate.

This result suggests that the degradation rate will be lower and consequently the mechanical properties will be maintained for longer time during the use of the blend in a biological medium.

The polyesters studied in this work are well known to be susceptible to hydrolytic and/or enzymatic bio absorption and their physical properties trends are coherent with the molecular weight changes during use. It is possible then to make easy drug delivery systems with good drug absorption kinetics [24-29] which can also be studied by software modeling and further description [30].

\subsection{FTIR-ATR spectroscopy}

Harada et al. [3], highlighted as this kind of reactive mixing brings to the formation of high molecular weight, grafted and/or cross linked, co-polyester-urethanes (see the reaction scheme of figure 9).

This is confirmed by the results above discussed, since it was found that the increase in the torque values, and hence in viscosity, is strictly related to the amount of LTI added, as it can be 
seen in the graph of figure $\mathbf{1 b}$ and table $\mathbf{I}$. Besides, the same data are also in agreement with the calorimetric data which suggest the formation of new structures with more amorphous (or less ordered) composition.

In order to better investigate about new structure composition, FTIR-ATR spectroscopy have been performed and discussed in the following. Figure 10 shows the change in FTIR-ATR spectra due to the LTI addition to the A50C50 blend. The stretching of carbonyl peak, around $1722 \mathrm{~cm}^{-1}$.

In the A50C50 blend, is shifted to $1720 \mathrm{~cm}^{-1}$ after the addition of 0,5 phr of LTI and to $1712 \mathrm{~cm}^{-1}$ after the addition of $1.0 \mathrm{phr}$. This confirms that new structures containing carbonyls (probably the carbamate groups - $\mathrm{NH}(\mathrm{CO}) \mathrm{O}-)$ are formed during the reactive mixing inside the mixer chamber. Carbamate groups originates from the reaction of $-\mathrm{OH}$ functional groups of polyesters and $\mathrm{N}=\mathrm{C}=\mathrm{O}$ functional groups of LTI.

It was expected, in particular for the highest amount of LTI, to find the characteristic peak of $\mathrm{N}=\mathrm{C}=\mathrm{O}$ at about $2270 \mathrm{~cm}^{-1}$, as this amount was considered to be in excess of the available $\mathrm{OH}$ groups. Its absence is however desirable as unreacted isocyanate groups are highly reactive and potentially toxic.

\section{Conclusions}

In this paper, we have reported a study on the effect of LTI as compatibilizing agent for PLA/PCL blends. Physical and mechanical features have been studied and compared before and after LTI addition in two different amounts (0.5 and $1.0 \mathrm{phr}$ ). The results highlight a synergicistic effect in the blends, thanks to the improved compatibility between the two polymeric phases. Compatibility increases by increasing the LTI amount In particular, the improvement in maximum deformation and breakage work evidenced a grown in ductility, while the improvement in yield stress and ultimate tensile strength highlighted an improvement in mechanical strength of the blends.

The ratio of PLA and PCL content in the compatibilized blends, results in materials with different properties that can be useful for different applications where specific strength, ductility and degradation rates are desired.

Due to the specific mechanical and physical features shown in this paper, our materials could be employed in the biomedical field as bio resorbable suture threads. Their high ductility, in fact, 
is important to allow the formation of knots with good mechanical resistance. In addition, knots must have a stiffness that can support the sealing of tissues without compromising their integrity

Torque, calorimetric and FTIR analyses all suggest the in-situ formation of a block-copolymer that acts as a compatibilizer.

Studies are in progress to check the blends stability during the application time, and to verify, their applicability in the specific as absorbable suture threads or scaffolds for cellular growth. In fact, further steps forward in applicative fields could be done by adding our reactive blends with other substances during their processing. For examples blends could be mixed with antibiotics or Vascular Endothelial Growth Factor (VEGF) with the aim to solve infections or to stimulate cellular growth. Alternatively, the use of ceramics or carbon nanofiller can give a further enhancement in stiffness and in mechanical strength for bone implants application.

\section{References}

[1] Dell’Erba, R., Groeninckx, G., Maglio, G., Malinconico, M., Migliozzi, A., 2001. Immiscible polymer blends of semi crystalline biocompatible components: thermal properties and phase morphology analysis of PLLA/PCL blends. Polymer. 42, 7831-7840. http://dx.doi.org/10.1016/S0032-3861(01)00269-5

[2] Wu, D., Zhang, Y., Zhang, M., Yu, W., 2009. Selective Localization of Multiwalled Carbon Nanotubes in Poly(e-caprolactone)/Polylactide Blend. Biomacromolecules. 10(2), 417-424. http://dx.doi.org/10.1021/bm801183f

[3] Wang, L., W., Ma, Gross, R. A., McCarthy, S. P., 1998. Reactive compatibilization of biodegradable blends of poly(lactic acid) and poly( e-aprolactone). Polym. Degrad. Stabil. 59 (1998).161-168. http://dx.doi.org/

[4] Harada, M., Iida, K., Okamoto, K., Hayashi, H., Hirano K., 2008. Reactive Compatibilization of Biodegradable Poly(lactic acid)/Poly(«-caprolactone)-Blends with Reactive Processing Agents. Polym. eng. and sci. 1359-1368. http://dx.doi.org/10.1002/pen.21088

[5] Naleway, S. E., Lear, W., Kruzic, J.J., Maughan C.B., 2015. Mechanical properties of suture materials in general and cutaneous surgery. J. Biomed. Mater. Res. Part B. 103B, 735-742. http://dx.doi.org/10.1002/jbm.b.33171

[6] Chu, C.C., 1981. Mechanical Properties of Suture Materials- An Important Characterization. Ann. Surg. 193(3),365-371. http://dx.doi.org/ 
[7] Urquijo, J., Guerrica-Echevarrìa, G., Eguiazàbal, J.I., 2015. Melt processed PLA/PCL blends: Effect of processing method on phase structure, morphology, and mechanical properties. J. Appl. Polym. Sci. 42641. http://dx.doi.org/ 10.1002/app.42641

[8] Tsuji, H., Yamada, T., Suzuki, M., Itsuno, S., 2003. Blends of aliphatic polyesters. Part 7. Effects of poly(L-lactide-co- $\varepsilon$-caprolactone) on morphology, structure, crystallization, and physical properties of blends of poly(L-lactide) and poly( $\varepsilon$-caprolactone). Polym. Int. 52, 269275. http://dx.doi.org/10.1002/pi.1093

[9] Tuba, F., Oláh, L., Nagy,P., 2011. Characterization of reactively compatibilized poly(D,Llactide)/poly(e-caprolactone) biodegradable blends by essential work of fracture method. Eng. Fract. Mech. 78, 3123-3133. http://dx.doi.org/10.1016/j.engfracmech.2011.09.010

[10] Takayama, T., Todo,M., Tsuji, H., 2011. Effect of annealing on the mechanical properties of PLA/PCL and PLA/PCL/LTI polymer blends. J. Mech. Beh. Biom. Mat. 4, 255-260. http://dx.doi.org/10.1016/j.jmbbm.2010.10.003

[11] Guelcher, S.A., Srinivasan, A., Dumas, J. E., Didier, J.E., McBride, S., Hollinger, J.O., 2008. Synthesis, mechanical properties, biocompatibility, and biodegradation of polyurethane networks from lysine polyisocyanates. Biomaterials. 29, 1762-1775.

http://dx.doi.org/10.1016/j.biomaterials.2007.12.046

[12] Hafeman, A. E., Zienkiewicz, K.J., Zachman, A.L., Sung, H.J., Nanney, L. B., Davidson, J.M., Guelcher, S.A., 2011. Characterization of the degradation mechanisms of lysine-derived aliphatic poly(ester urethane) scaffolds. Biomaterials. 32, 419-429

http://dx.doi.org/10.1016/j.biomaterials.2010.08.108

[13] Cohn,D., Salomon, A.H. 2005. Designing biodegradable multiblock PCL/PLA

thermoplastic elastomers. Biomaterials, 26, 2297-2305.

http://dx.doi.org/10.1016/j.biomaterials.2004.07.052

[14] Storey R. F., Wiggins J.S., Mauriz K.A., Puckett A.D. 1993. Bioabsorbable Composites. II: Nontoxic, L-lysine-based Poly(ester-urethane) matrix composites. Polym. Composite, 14(1): $17-25$.

[15] Schreader, K.J., Bayer, I.S., Milner, D.J., Loth, E., Jasiuk, I., 2013. A Polyurethane-Based Nanocomposite Biocompatible Bone Adhesive. J. Appl. Polym. Sci.,127(6): 4974-4982. http://dx.doi.org/10.1002/app.38100 
[16] Zhang, J.Y., Beckman, E.J., Hu, J., Yang, G.G. Agarwal, S., Hollinger, J.O., 2002. Synthesis, Biodegradability, and Biocompatibility of Lysine Diisocyanate-Glucose Polymers Tissue Eng., 8(5): 771-785. http://dx.doi.org/10.1089/10763270260424132

[17] Gabriele Perego, Gian Domenico Cella, Catia Bastioli, 1996. Effect of molecular weight and crystallinity on poly(lactic acid) mechanical properties. J. Appl. Polym. Sci. 59:37-43 http://dx.doi.org/ 10.1002/(SICI)1097-4628(19960103)59:1<37::AID-APP6>3.0.CO;2-N

[18] Bayer,I.S., Ghosh, A., Labriola, M., Biris, A.S., Dervishi, E., Watanabe, F., Wang, T., Slaboch,f C., Ovaertf T.C, Biswas, A., 2013. Fabrication of bionanocomposites comprising flat nanocrystals of calcium in collagen fibers exhibiting hardness comparable to metal. RSC Adv., 3: 20315-20323 . http://dx.doi.org/10.1039/c3ra43121e

[19] Pillin, I., Montrelay, N., Bourmaud, A., Grohens, Y., 2008. Effect of thermo-mechanical cycles on the physico-chemical properties of poly(lactic acid). Polym. Degrad. Stabil. 93: 321328 . http://dx.doi.org/10.1016/j.polymdegradstab.2007.12.005

[20] Visco,A.M., Torrisi,L., Campo,N., Emanuele,U., Trifirò,A., Trimarchi,M., 2009. Mechanical Performance of Electron-Beam-Irradiated UHMWPE in Vacuum and in Air. J. Biomed. Mater. Res. B. 89 B (1) 55-64

http://dx.doi.org/10.1002/jbm.b.31187

[21] Yousef, S., Visco, A.M., Galtieri, G., Nocita, D., Espro, C., 2016 (In press). Wear behavior of UHMWPE reinforced by carbon nanofiller and paraffin oil for joint replacement. J. Mat. Sci. Eng. C. http://dx.doi.org/10.1016/j.msec.2016.11.088

[22] Torrisi,L., Gentile,C., Visco,A.M., Campo,N. 2003. Wetting modifications of UHMWPE surfaces induced by ion implantation. Radiat. Eff. Defect S. 158, 731-741.

http://dx.doi.org/10.1080/10420150310001599090

[23] Nerem, R.M., Seliktar, D., 2001. Vascular Tissue Engineering. Annu. Rev. Biomed. Eng. 3, 225-43. http://dx.doi.org/10.1146/annurev.bioeng.3.1.225

[24] Michael, F.M., Khalida,M., Walvekar,R., Ratnamc, C.Y., Ramarad, S., Siddiqui,H., Enamul Hoque,M., 2016. Effect of nanofillers on the physico-mechanical properties of load bearing bone implants. J. Mat. Sci. Eng. C. 67, 792-806. http://dx.doi.org/10.1016/j.msec.2016.05.037 
[25] Vieira, A.C., Vieira, J.C., Ferra, J.M., Magalhães, F.D., Guedes, R.M., Marques, A.T., 2011. Mechanical Study of PLA-PCL Fibers during In Vitro Degradation. J. Mech. Beh. Biom. Mat. 4, 451-460. http://dx.doi.org/10.1016/j.jmbbm.2010.12.006

[26] Karuppuswamy,P., Venugopal, J.R., Navaneethan,B., Laiva, A.L., Ramakrishna,S., 2015. Polycaprolactone nanofibers for the controlled release of tetracycline hydrochloride. Mater. Lett. 141, 180-186. http://dx.doi.org/10.1016/j.matlet.2014.11.044

[27] Zahedi, P., Karami, Z., Rezaeian, I., Jafari, S.H., Mahdaviani, P., Abdolghaffari, A.H., Abdollahi, M., 2012. Preparation and Performance Evaluation of Tetracycline Hydrochloride Loaded Wound Dressing Mats Based on Electrospun Nanofibrous Poly(lactic acid)/Poly( $\alpha-$ caprolactone) Blends. J. Appl. Polym. Sci. 124, 4174-4183. http://dx.doi.org/ 10.1002/app.35372

[28] Perale, G., Casalini, T., Barri, V., Muller, M., Maccagnan, S., Masi, M., 2010. Lidocaine release from polycaprolactone threads. J. Appl. Polym. Sci. 117(6) 3610-3614. http://dx.doi.org/10.1002/app

[29] Catanzano, O., Acierno , S., Russo , P., Cervasio, M., Del Basso De Caro, M., Bolognese, A., Sammartino, G., Califano, L., Marenzi, G., Calignano, A., Acierno, D., Quaglia, F., 2014 Melt-spun bioactive sutures containing nanohybrids for local delivery of anti-inflammatory drugs. Mat. Sci. Eng. C. 43, 300-309. http://dx.doi.org/10.1016/j.msec.2014.07.012

[30] Casalini, T., Masi, M., Perale, G., 2012. Drug eluting sutures: A model for in vivo estimations. Int. J. Pharm. 429:148-157. http://dx.doi.org/10.1016/j.ijpharm.2012.03.024. 

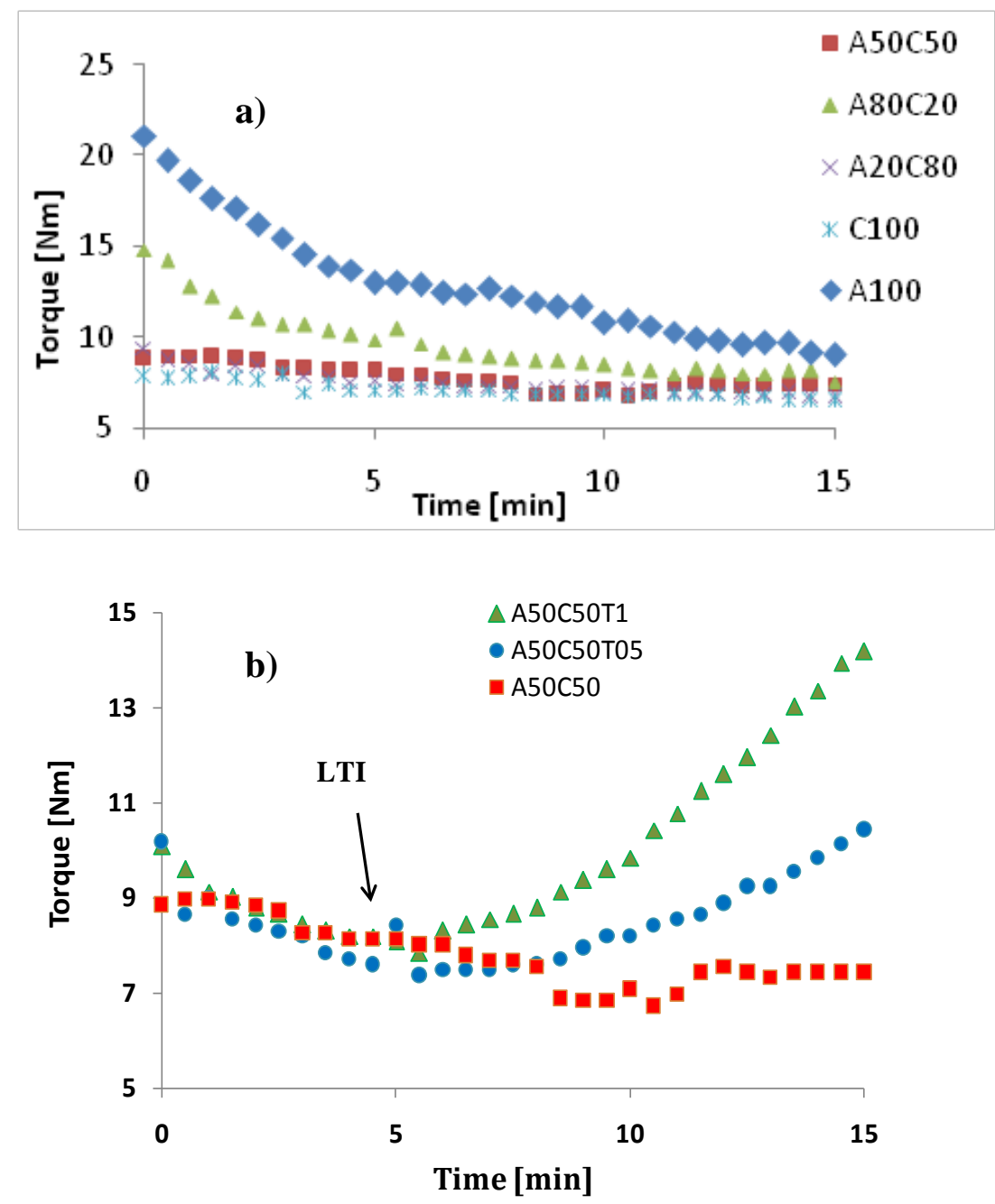

Figure 1- Torque trends during mixing time of pure polymers and blends (a); of A50C50 blend before and after the addition of different amounts of LTI compatibilizer (b). 


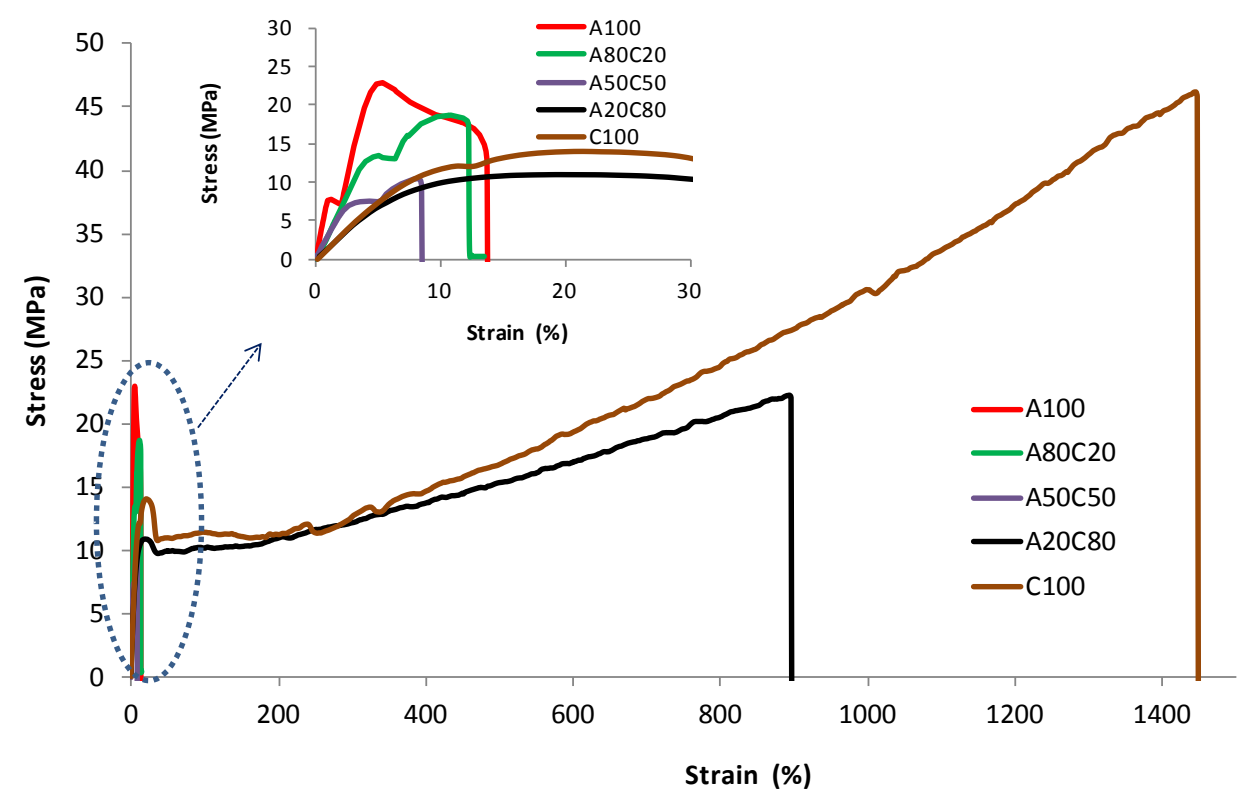

Figure 2 - Stress Strain curves for pure materials and un-compatibilized blends 

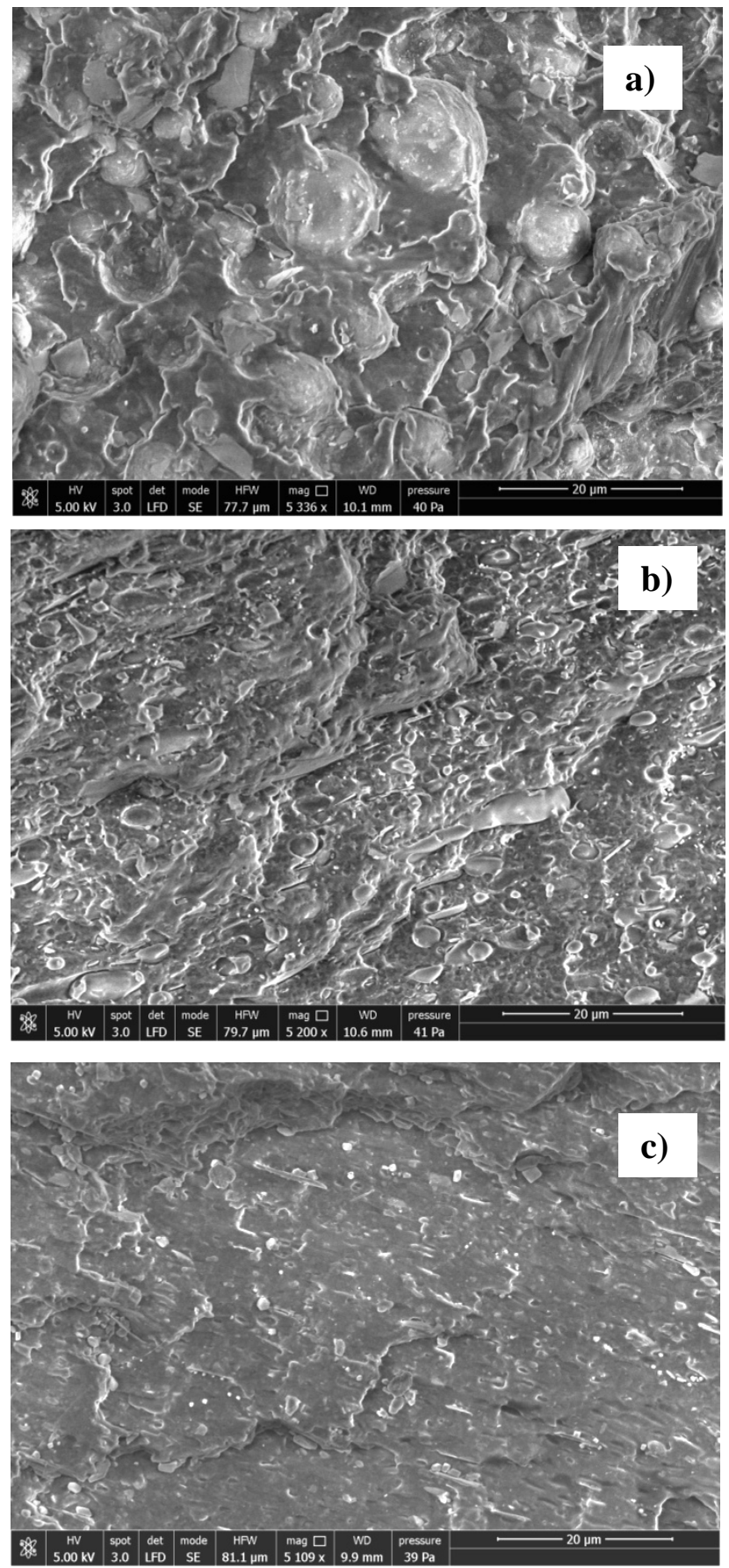

Figure 3 -SEM micrographs of A50C50 blend un-compatibilized (a), and compatibilized with $0.5 \mathrm{phr}(\mathrm{b})$ and $1 \mathrm{phr}(\mathrm{c})$ 


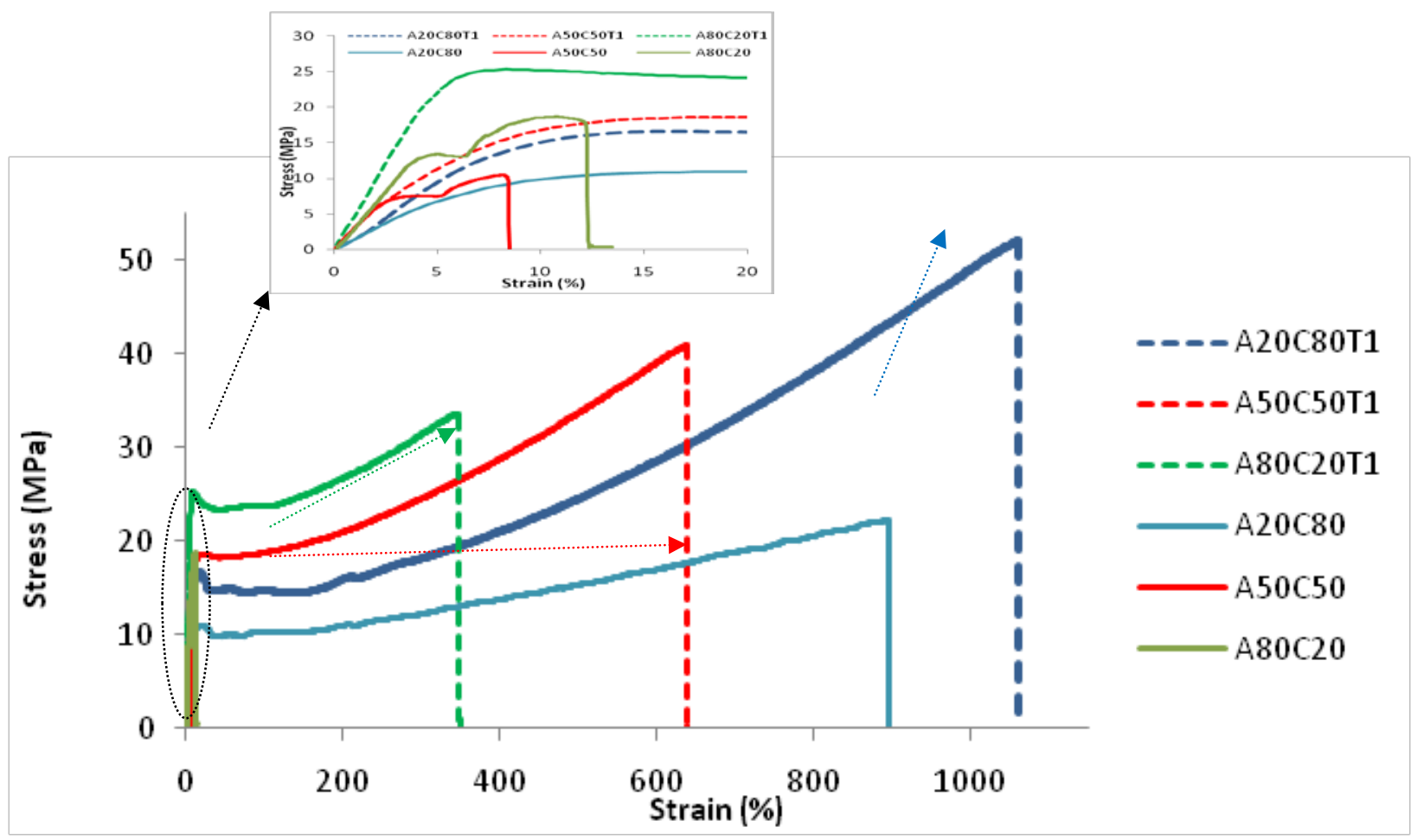

Figure 4 - Stress Strain curves for pure and compatibilized blends 

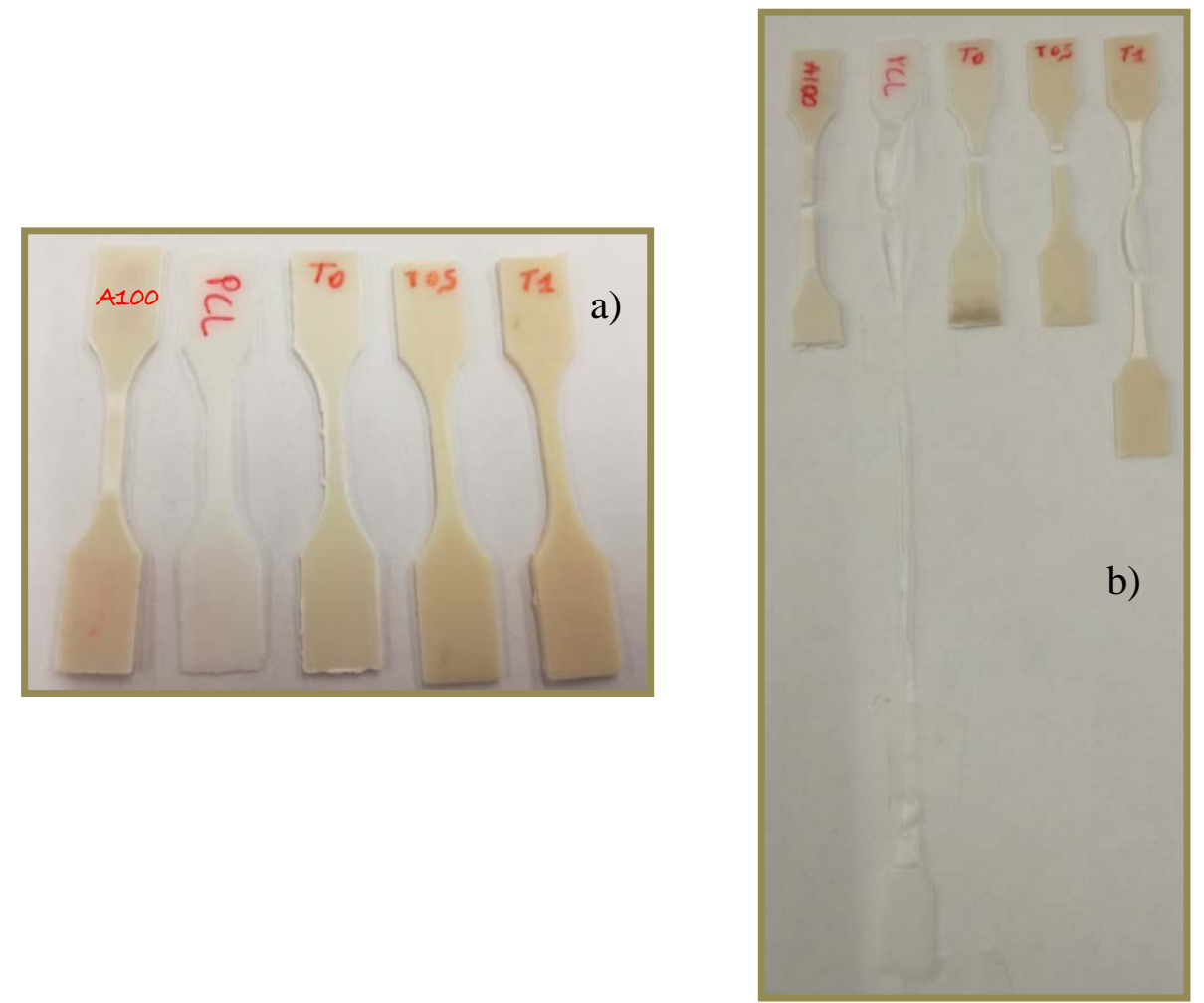

Figure 5 -Image of a dog bone sample of A100, C100, A50C50, A50C50T0.5, A50C50T1.0 before (a) and after (b) a tensile test. 

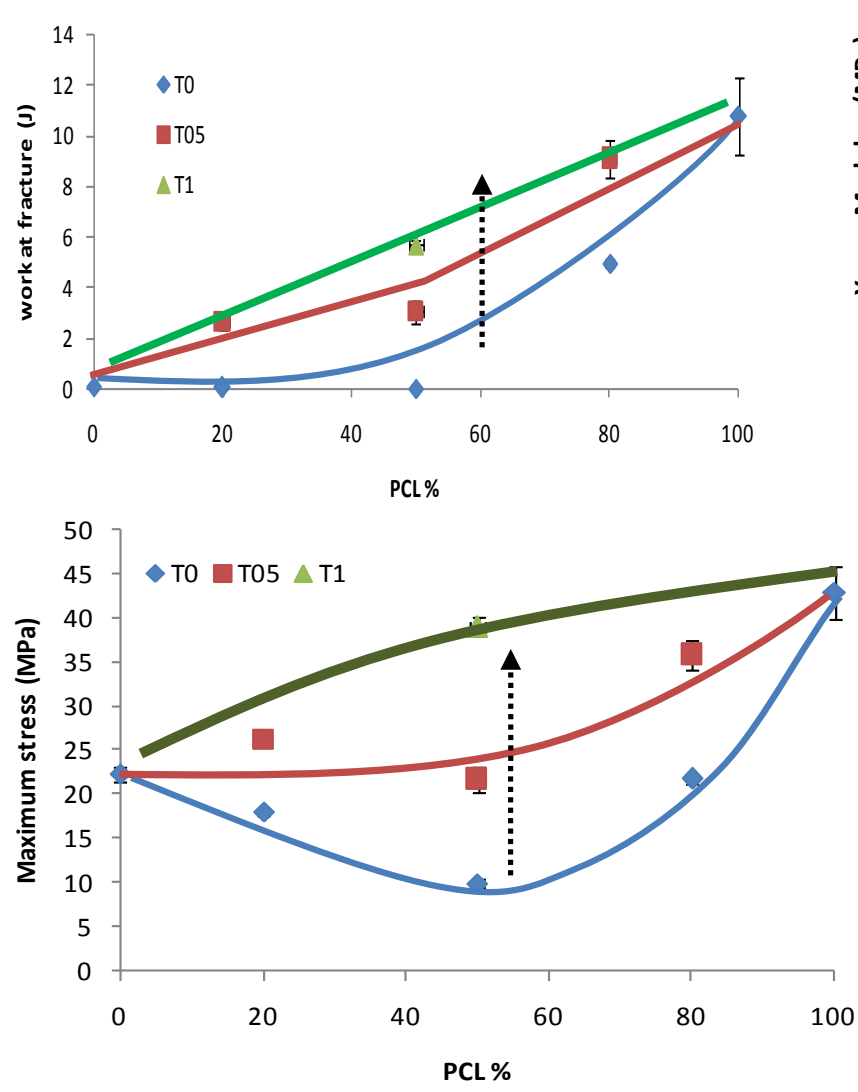
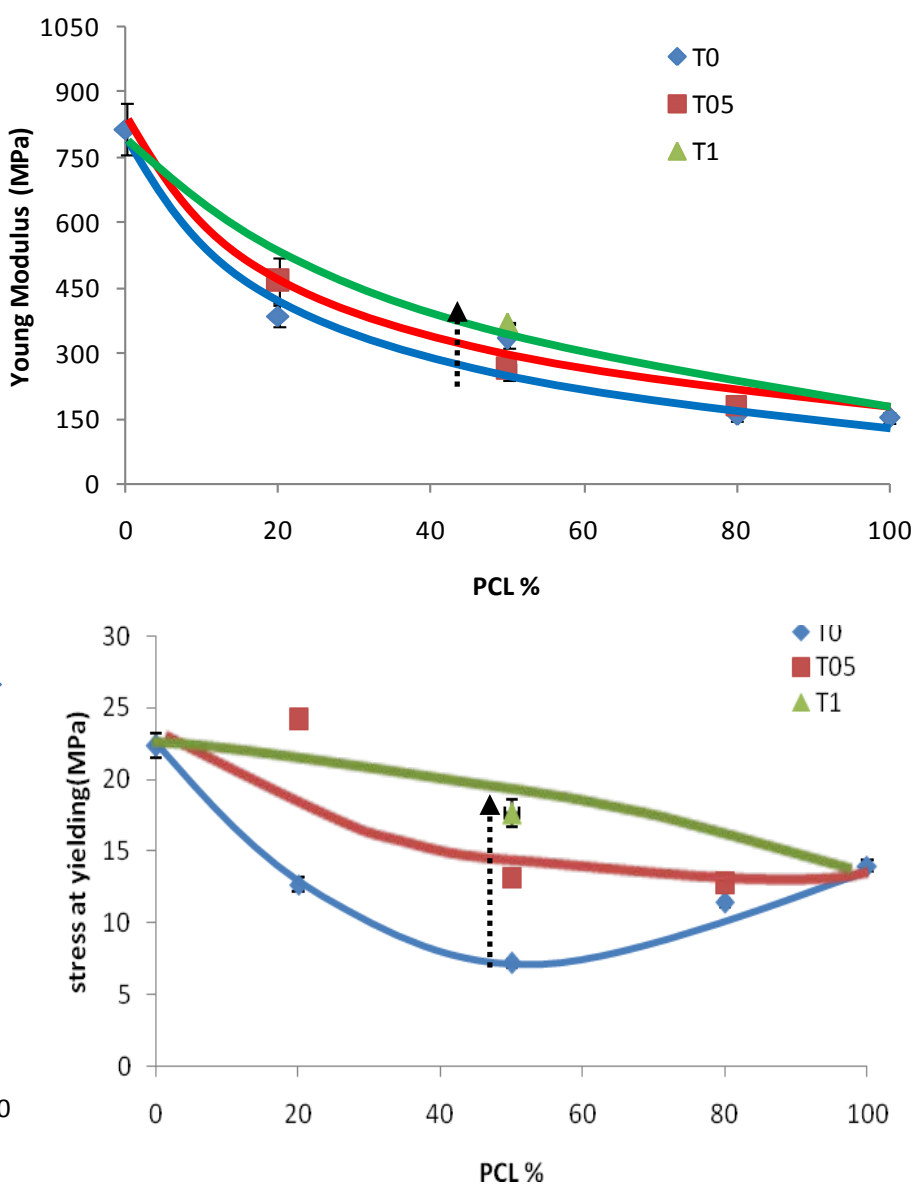

Figure 6-Work at fracture (a),Young Modulus (b), maximum stress (c) and stress at yielding (d) for all the blends (pure,T0.5 and T1) as a function of the PCL content. 


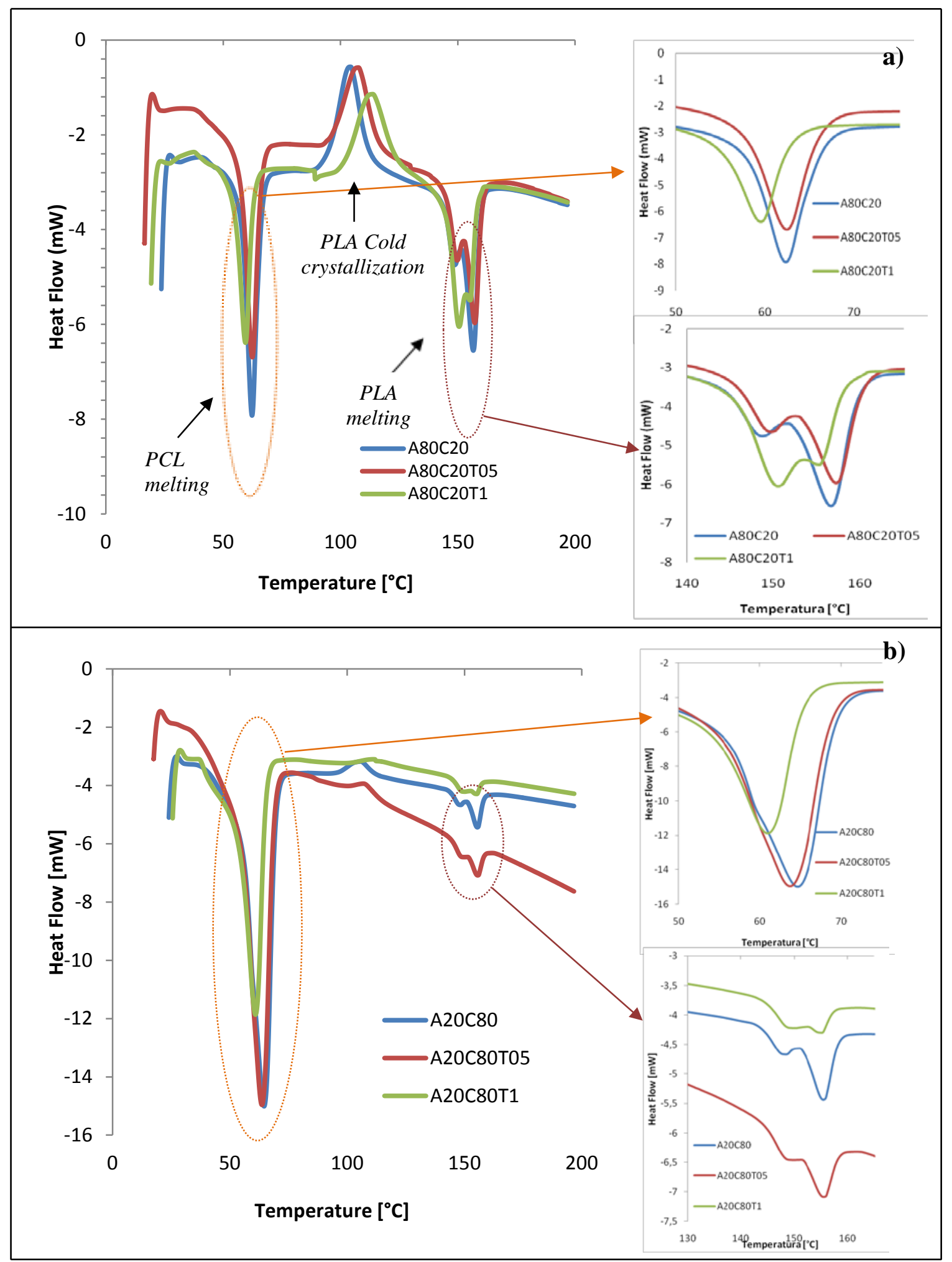

Figure 7 - DSC spectra of pure and compatibilized A80C20 (a) and A20C80 blends (b) in the left with and expansion of two peaks in the right. 


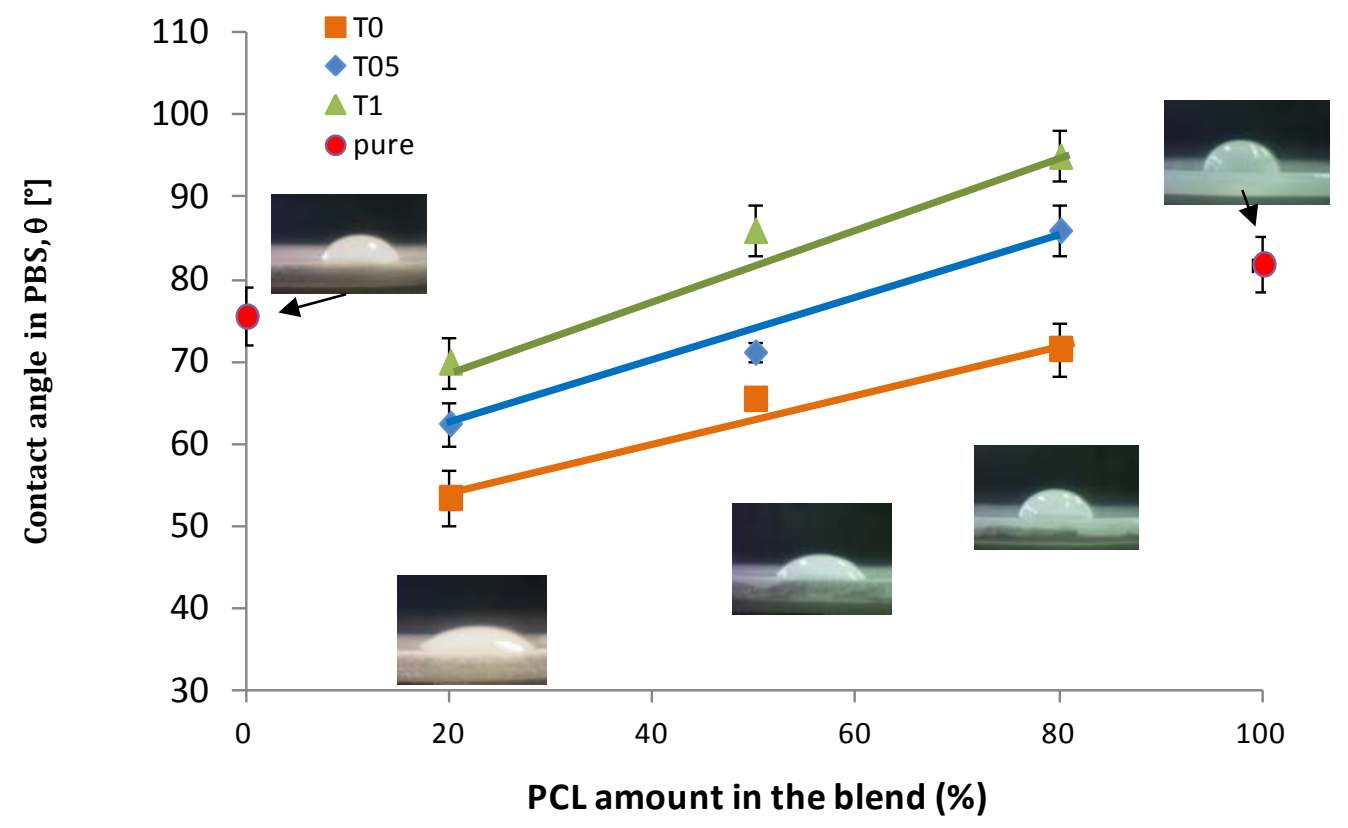

Figure 8 - Contact angle in PBS as a function of PCL amount and of the LTI amount 


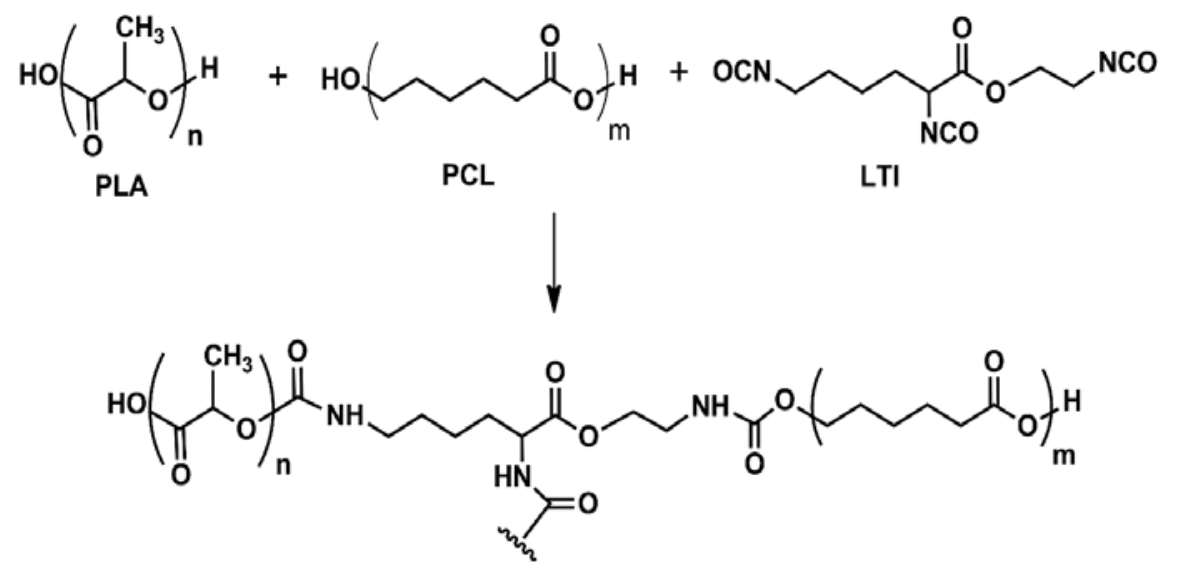

Figure 9 - Reaction Scheme for PLA - PCL - LTI 

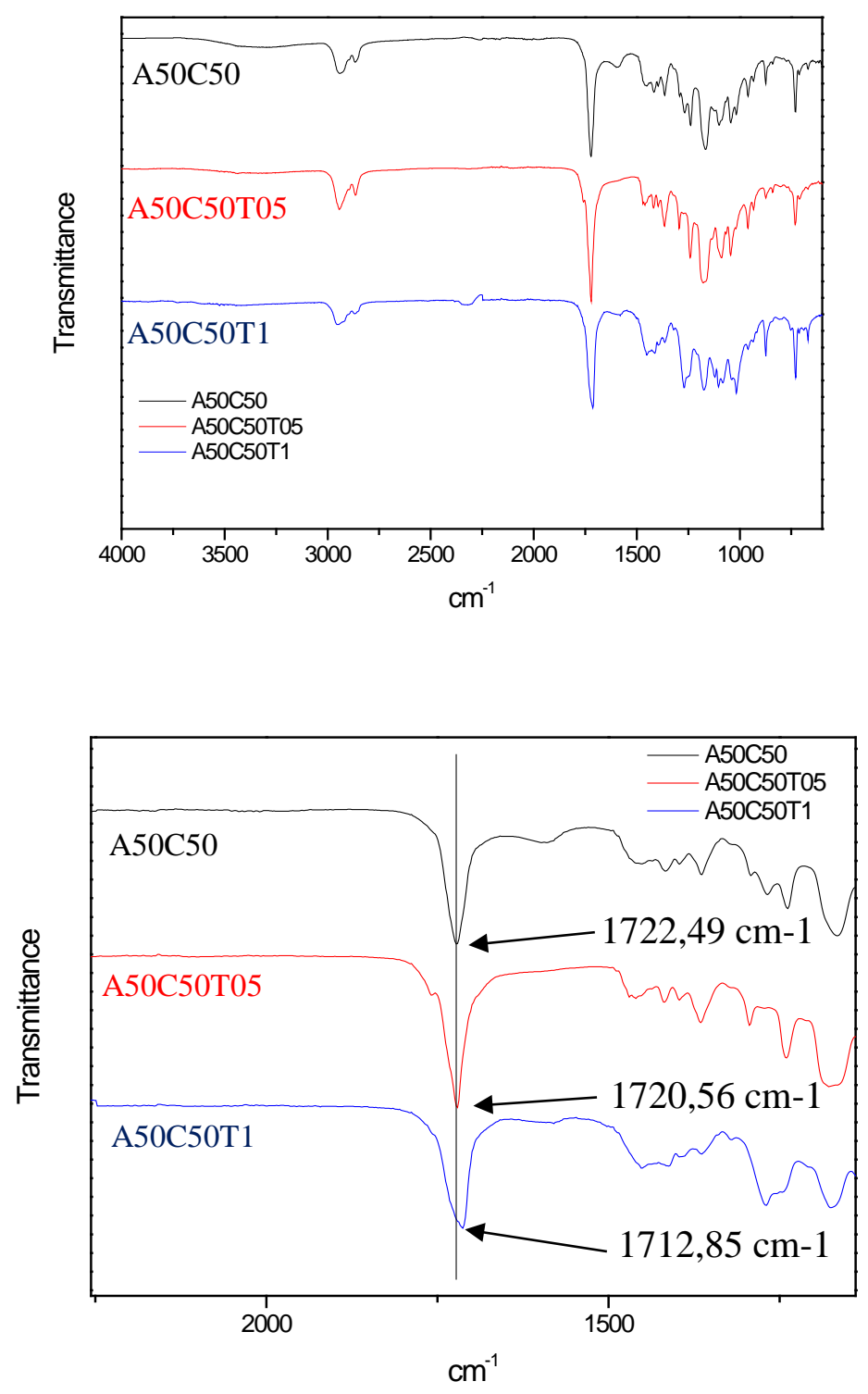

Figure 10- ATR Spectra of A50C50, A50C50T0.5 and A50C50T1 